\title{
Computed tomography parameters for atlantooccipital dislocation in adult patients: the occipital condyle-C1 interval
}

\author{
Eduardo Martinez-del-Campo, MD, ${ }^{1}$ Samuel Kalb, MD, ${ }^{1}$ Hector Soriano-Baron, MD, ${ }^{1}$ \\ Jay D. Turner, MD, PhD, ${ }^{1}$ Matthew T. Neal, MD, ${ }^{1}$ Timothy Uschold, MD, ${ }^{2}$ and \\ Nicholas Theodore, MD' \\ 'Division of Neurological Surgery, Barrow Neurological Institute, St. Joseph's Hospital and Medical Center, Phoenix, Arizona; and \\ ${ }^{2}$ Southern Oregon Neurosurgical and Spine Associates, Medford, Oregon
}

OBJECT Atlantooccipital dislocation (AOD) in adults cannot be diagnosed with adequate specificity and sensitivity using only CT or plain radiography, and the spine literature offers no guidelines. In children, the most sensitive and specific radiographic measurement for the diagnosis of $A O D$ is the $\mathrm{CT}$-based occipital condyle- $\mathrm{C} 1$ interval (CCI). The goal of the current study was to identify the normal $\mathrm{CCl}$ in healthy adults and compare it with the $\mathrm{CCl}$ in adults with $\mathrm{AOD}$ to establish a highly sensitive and specific cutoff value for the neuroimaging diagnosis of AOD.

METHODS A total of 81 patients, 59 without AOD and 22 with AOD, were included in this study. Measurements obtained from thin-slice CT scans of the craniovertebral joint to assess atlantooccipital dislocation included the $\mathrm{CCl}$, condylar sum, the Wholey and Harris intervals, Powers and Sun ratios, Wackenheim line, and Lee X-lines.

RESULTS The group of patients without AOD included 30 men $(50.8 \%)$ and 29 women $(49.2 \%)$ with a mean age of 42.4 \pm 16 years (range 19-87 years). The group of patients with AOD included 10 men (45.5\%) and 12 women (54.5\%) with a mean age of $38.2 \pm 9.7$ years (range $20-56$ years). Interrater reliabilities within a $95 \% \mathrm{Cl}$ were all greater than 0.98 for $\mathrm{CCl}$ measurements. A total of 1296 measurements of the $\mathrm{CCl}$ were made in 81 patients. The mean $\mathrm{CCl}$ for non-AOD patients was $0.89 \pm 0.12 \mathrm{~mm}$, the single largest CCl measurement was $1.4 \mathrm{~mm}$, and the largest mean for either right or left $\mathrm{CCl}$ was $1.2 \mathrm{~mm}$. The mean condylar sum was $1.8 \pm 0.2 \mathrm{~mm}$, and the largest condylar sum value was $2.2 \mathrm{~mm}$. Linear regression with age predicted an increase in $\mathrm{CCl}$ of $0.001 \mathrm{~mm} /$ year $(p<0.05)$. The mean $\mathrm{CCl}$ in AOD patients was 3.35 $\pm 0.18 \mathrm{~mm}$ (range $1.5 \mathrm{~mm}-6.4 \mathrm{~mm}$ ). The shortest single CCI measurements in the AOD patients were $1.1 \mathrm{~mm}$ and 1.2 $\mathrm{mm}$. The mean condylar sum for all $22 \mathrm{AOD}$ patients was $6.7 \pm 2.7 \mathrm{~mm}$ and the shortest condylar sums were $3.0 \mathrm{~mm}$. Cutoff values for AOD were set at $1.5 \mathrm{~mm}$ for the $\mathrm{CCl}$ and $3.0 \mathrm{~mm}$ for the condylar sum, both with a sensitivity of 1 and false-negative rate of 0 . Sensitivity for the Powers, Wholey, Harris, Sun, Wackenheim, and Lee criteria were determined to be $0.55,0.46,0.27,0.23,0.41$, and 0.41 , respectively.

CONCLUSIONS The CCl is shorter in adult patients as opposed to the pediatric population. The revised $\mathrm{CCl}(1.5 \mathrm{~mm})$ and condylar sum $(3.0 \mathrm{~mm})$ cutoff values have the highest sensitivity and specificity for the diagnosis of AOD in the adult population.

http://thejns.org/doi/abs/10.3171/2015.6.SPINE15226

KEY WORDS occipital; condyle; C-1; adults; atlantooccipital; dislocation; cervical

$\mathrm{U}$ PPER cervical spine injuries account for 56\%-73\% of all cervical traumas. ${ }^{8,9,12-14,16,17,19,21,25,32}$ One type of upper cervical spine injury, atlantooccipital dislocation (AOD), is a severe injury associated with high mortality rates. ${ }^{1,2,11,12,16-20,22,24}$ In postmortem examinations, evidence of AOD is present in $20 \%-31 \%$ of deaths due to cervical spine injuries. ${ }^{6}$ In recent decades, improvements in emergency management, transport, and recognition of AOD have resulted in higher survival rates. ${ }^{11,28}$ Plain radiography and CT scans are typically the initial screening studies in the trauma population, but, unfortunately, there are no published guidelines for their use that afford

ABBREVIATIONS AOD = atlantooccipital dislocation; $\mathrm{ASIA}=$ American Spinal Injury Association; $\mathrm{BAI}=$ basion axial interval; $\mathrm{BDI}=$ basion-dental interval; $\mathrm{CCl}=$ occipital condyle-C1 interval; $\mathrm{CVJ}=$ craniovertebral junction; $\mathrm{LCCl}=$ left CCl; Oc-C1 = occiput-C1; $\mathrm{RCCl}=$ right $\mathrm{CCl} ; \mathrm{ROC}=$ receiver operating characteristic.

SUBMITTED February 23, 2015. ACCEPTED June 17, 2015.

INCLUDE WHEN CITING Published online December 18, 2015; DOI: 10.3171/2015.6.SPINE15226. 
adequate specificity and sensitivity when assessing adult patients with AOD.

Several radiographic criteria have been proposed to diagnose AOD based on lateral cervical radiographs and CT scans. According to the latest guidelines for AOD published in $2013,{ }^{28}$ the basion axial interval-basion dental interval (BAI-BDI) method described by Harris et al..$^{10}$ is the most reliable way of diagnosing AOD on lateral cervical radiographs. Because the BAI-BDI method has a sensitivity of only $50.5 \%$, a large portion of patients will require additional confirmatory imaging.

In children, the most sensitive and specific test to diagnose AOD is the CT-based occipital condyle-C1 interval (CCI)..$^{18,19,28,30}$ In 2007, Pang et al. ${ }^{18,19}$ studied the CCI in 89 children without AOD and 16 children with AOD. They reported that a normal CCI was $1.28 \pm 0.26 \mathrm{~mm}$ and proposed a CCI $\geq 4 \mathrm{~mm}$ as diagnostic for AOD. They found the CCI to have a sensitivity and specificity of $100 \%$ compared with other standard diagnostic tests including the Powers $^{23}$ ratio, Wholey ${ }^{31}$ method, Harris ${ }^{10}$ BAI-BDI, and Sun $^{27}$ interspinous ratio.

Several authors have suggested that in adults a $\mathrm{CCI} \geq 2$ $\mathrm{mm}$ is abnormal. ${ }^{5,26,28}$ More recently, Gire et al. ${ }^{7}$ proposed that a single measurement of the CCI $\geq 2.5 \mathrm{~mm}$ and/or a condylar sum $\geq 5 \mathrm{~mm}$ was indicative of AOD in their analysis of 10 patients ( 6 adults and 4 children). ${ }^{7}$ We believe that an adequate study should attempt to identify the $\mathrm{CCI}$ in healthy adult patients and compare it with the CCI in adult patients with AOD. Although a few studies address this topic, ${ }^{28,30}$ to our knowledge, this paper presents the largest CT-based study evaluating normal and abnormal parameters for the CCI exclusively in the adult population. We report the CCI for 59 adults without AOD and for 22 adults with AOD and compare their results with published radiological diagnostic criteria $a^{7,10,15,18,19,23,27,31}$ to determine whether a highly sensitive and specific cutoff value for diagnosing AOD with neuroimaging studies can be defined.

\section{Methods}

This is a retrospective systematic review study approved by the institutional review board at St. Joseph's Hospital and Medical Center, Phoenix, Arizona. Data from 81 adult patients were included in the study.

\section{Patient Characteristics}

The control group comprised 59 consecutive patients who were defined as non-AOD based on the following criteria: patients who were admitted through the emergency department with minor or no upper-body trauma, who had no cervical pain or evidence of neurological deficits, and who had a thin-slice CT scan of the craniovertebral junction (CVJ) between April 1 and May 31, 2014. If patients developed neurological symptoms or cervical pain at any time during their hospital stay, they were excluded from the study.

The AOD group comprised 22 patients selected according to the following criteria: patient experienced high-energy or blunt trauma to the CVJ, had serial MRI evidence of ligamentous injury consistent with instability (tectorial membrane disruption and/or disruption of the occiput-C1 [Oc-C1] joint capsule), ${ }^{4}$ underwent surgical internal fixation of the CVJ with intraoperative confirmation of $\mathrm{Oc}-\mathrm{C} 1$ junction instability, and had thin-slice CT scans of the CVJ at presentation between June 2007 and September 2012.

Of the 22 patients in the AOD cohort, 1 patient (4.5\%) had American Spinal Injury Association (ASIA) Grade A function, 1 patient $(4.5 \%)$ had ASIA Grade B, 5 patients (22.7\%) had ASIA Grade C, 7 patients (31.8\%) had ASIA Grade D, 6 patients (27.3\%) has ASIA Grade E, and 2 patients $(9 \%)$ could not be tested due to unfavorable clinical presentations.

\section{Craniovertebral Junction Measurements}

Measurements were made by 2 physicians from the Division of Neurological Surgery at Barrow Neurological Institute, Phoenix, Arizona, who were blinded to the patients' diagnoses.

\section{Occipital Condyle-C1 Interval}

Based on the method described by Pang et al., ${ }^{18,19}$ a total of 1296 measurements were made of the CCIs in 81 patients. To determine the CCI for both the right and left sides, the distance between the cortex of the occipital condyle and the upper endplate of C-1 was measured 4 times on parasagittal and 4 times on coronal CT scans (Fig. 1). The contralateral joint was then measured. In some cases, a wedge-shaped crevice was evident on the $\mathrm{Oc}-\mathrm{C} 1$ junction. This crevice was avoided when selecting measurement points.

The combined CCI for each side (right and left CCI)

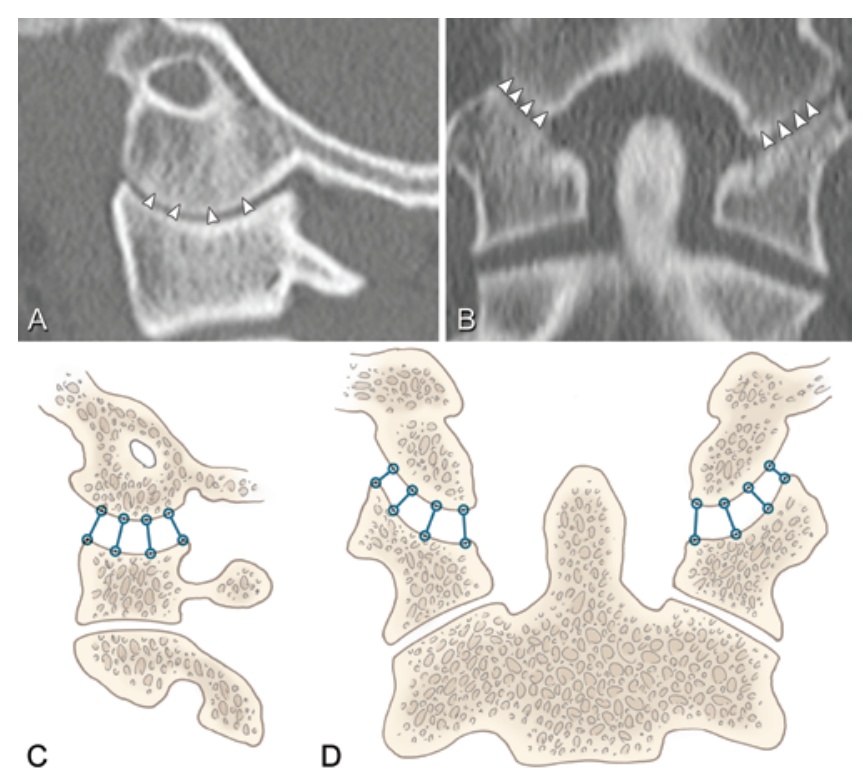

FIG. 1. A and B: Parasagittal and coronal CT scans of the Oc-C1 joint, with 4 equidistant arrowheads measuring the $\mathrm{CCl}$ distance between the cortex of the occipital condyle and the superior endplate of $\mathrm{C}-1$. C and D: Parasagittal and coronal illustrations of this joint show 4 equidistant lines measuring the same distance. Panels $C$ and D: Copyright Barrow Neurological Institute, Phoenix, Arizona. Used with permission. Figure is available in color online only. 
was the mean of the 8 measurements taken for the side. The condylar sum was defined as the sum of the left and right mean CCI values for each patient.

\section{Standard Diagnostic Criteria for AOD}

Figure 2 illustrates important landmarks of the CVJ. Comparative evaluation of the CCI was performed using standard radiological AOD diagnostic criteria for all the patients ${ }^{3,18,19,28}$ including the Wholey ${ }^{31}$ BDI, Powers ${ }^{23}$ ratio, Harris $^{10}$ BAI, Sun ${ }^{27}$ interspinous ratio, Wackenheim ${ }^{29}$ line, and Lee ${ }^{15} \mathrm{X}$-lines.

Wholey Line. The BDI is the distance between the basion (point $\mathrm{B}$ ) and the dens (point $\mathrm{D}$ ), and it is suggestive of AOD when $\geq 12 \mathrm{~mm}$ (Fig. 3). Normal parameters range from $0 \mathrm{~mm}$ to $<12 \mathrm{~mm}$.

Harris Line. The BAI is the distance between a tangential line to the posterior wall of the C-2 vertebral body (posterior axial line) and a line parallel to it in contact with the basion. A BAI $\geq 12 \mathrm{~mm}$ is suggestive of AOD (Fig. 3). Normal parameters range from $-4 \mathrm{~mm}$ to $<12$ $\mathrm{mm}$. Negative values are obtained when the parallel line is dorsal to the posterior axial line.

Powers Ratio. This is the ratio of the distance between the basion and the posterior atlas arch (BC1) line divided by the opisthion to anterior atlas arch (OA) line and is suggestive of $\mathrm{AOD}$ when $\mathrm{BC} 1 / \mathrm{OA}$ is $\geq 1.0$ (Fig. 4). Normal parameters range from 0 to $<1.0$.

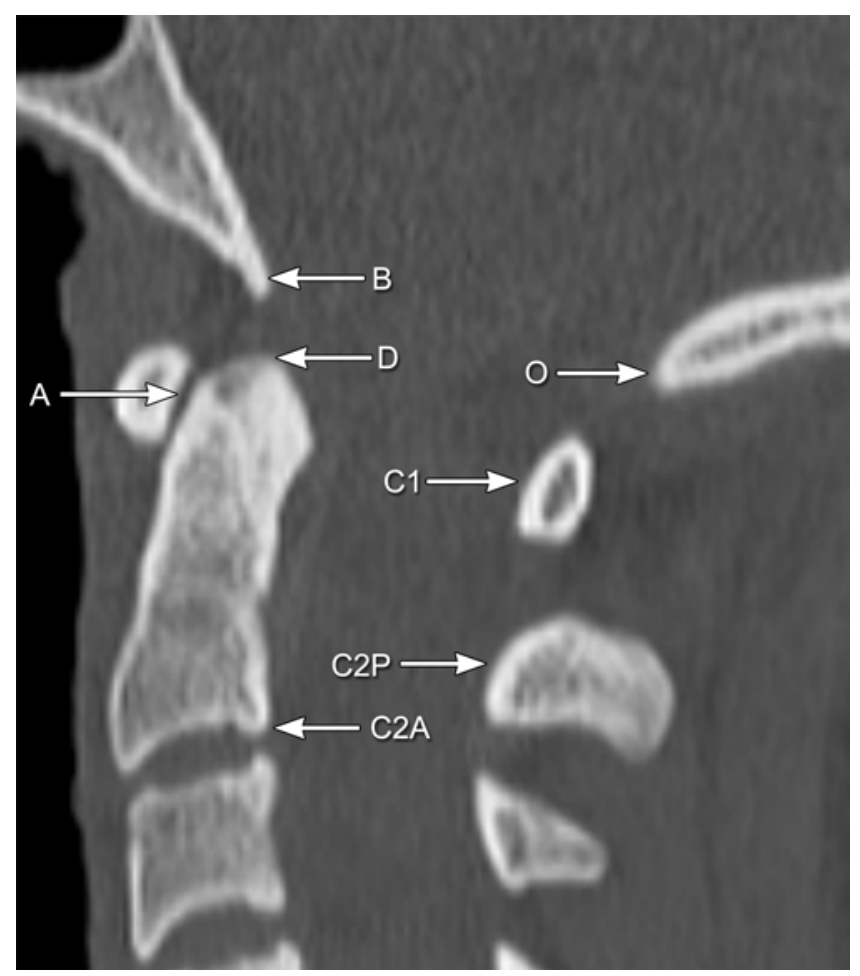

FIG. 2. Important landmarks of the Oc-C1 junction on a midsagittal CT scan, identifying the basion (B), opisthion (O), the uppermost portion of the dens $(D)$, the midpoint of the inner table of the posterior $(C)$ and anterior $(\mathrm{A})$ arch of $\mathrm{C}-1$, the axis spinolaminar junction (C2P), and the posterior inferior corner of the body of $\mathrm{C}-2(\mathrm{C} 2 \mathrm{~A})$.

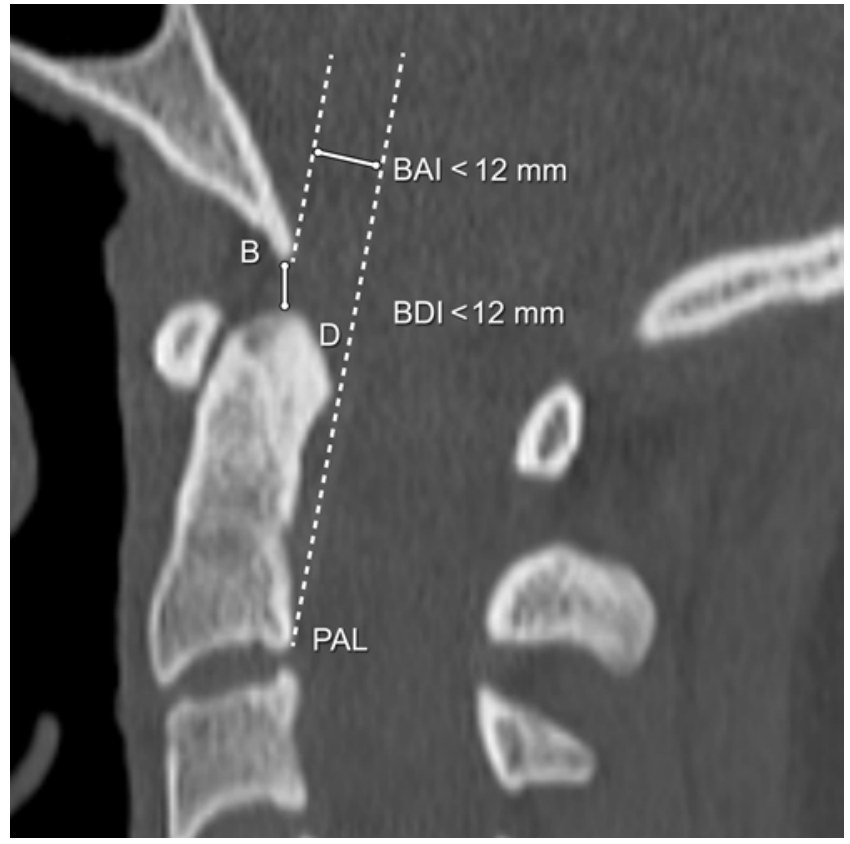

FIG. 3. Midsagittal CT scan of the upper cervical spine depicting the Wholey BDI and Harris BAI lines. Values $<12 \mathrm{~mm}$ are not suggestive of $A O D$. $P A L=$ posterior atlantal line.

Sun Ratio. This is the ratio of the interspinous distance between $\mathrm{C}-1$ and $\mathrm{C}-2$ divided by the distance between $\mathrm{C}-2$ to $\mathrm{C}-3$ and is suggestive of AOD when the ratio is $\geq 2.5$ (Fig. 5). Normal parameters range from 0 to $<2.5$. The

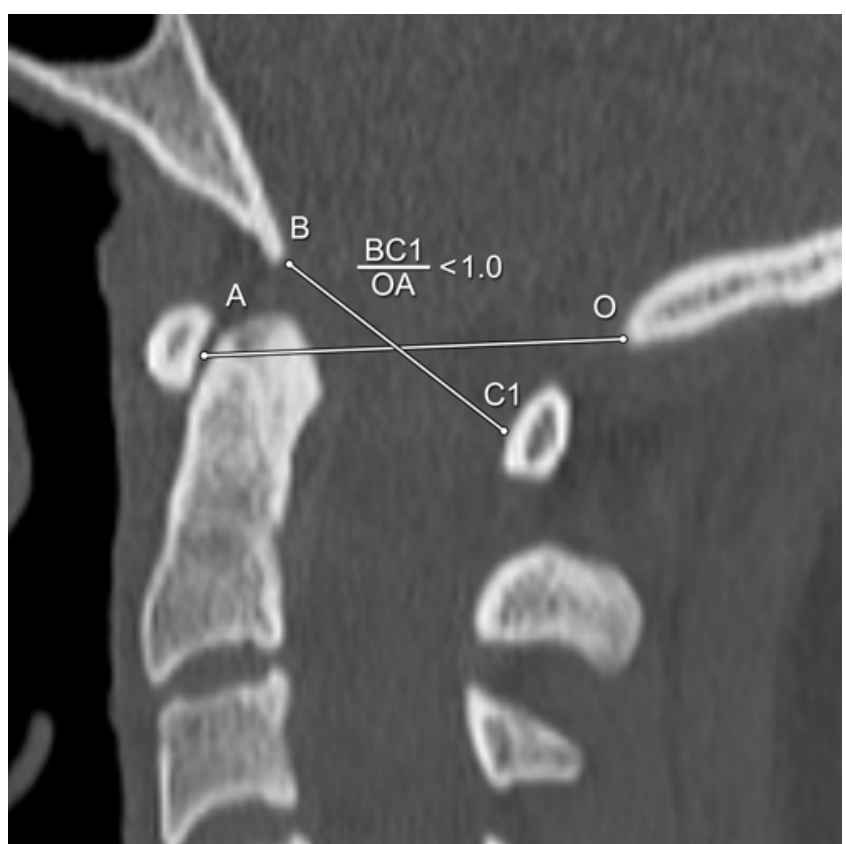

FIG. 4. Midsagittal CT scan of the upper cervical spine depicting the Powers ratio: the ratio of the distance between the basion and the posterior atlantal arch (BC1) divided by the opisthion to anterior atlas arch $(\mathrm{OA})$ line $(\mathrm{BC} 1 / \mathrm{OA})$. Values < 1 are not suggestive of $A O D$. 


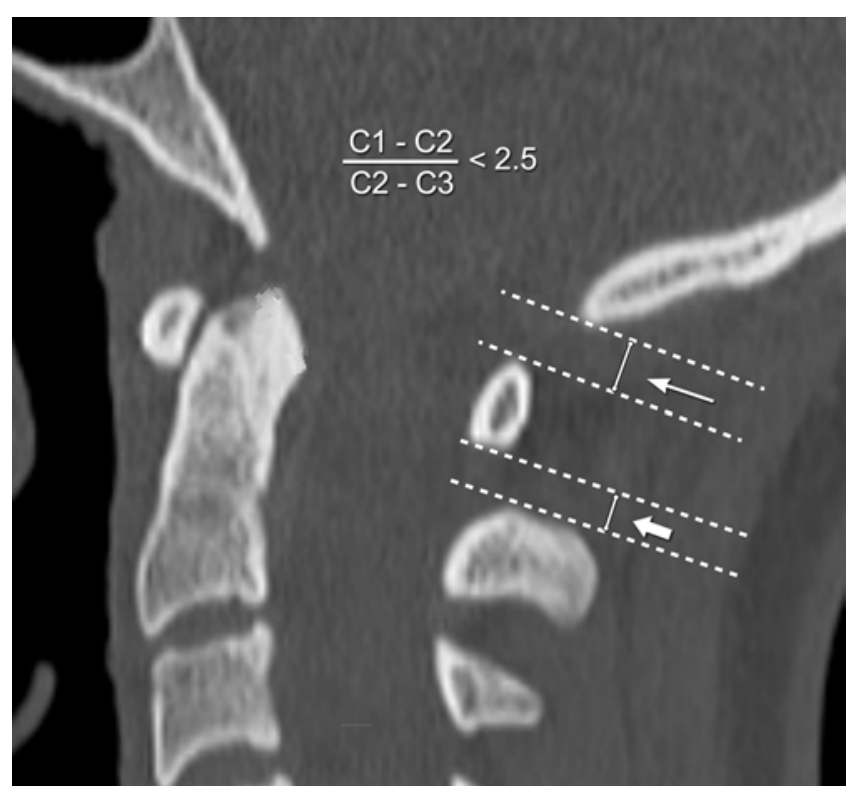

FIG. 5. Midsagittal CT scan of the upper cervical spine depicting the Sun ratio (distance from $\mathrm{C}-1$ to $\mathrm{C}-2$ [thin arrow] divided by the distance from C-2 to C-3 [thick arrow]). Values $<2.5$ are not suggestive of AOD.

C-2 and C-3 transverse processes are bifid, and our estimations were made using parasagittal CT images.

Wackenheim Line. This is a tangential line extended from the clivus and is considered normal when it intersects with the dens (Fig. 6). If the line fails to intersect with the dens, it is suggestive of AOD.

Lee $X$-Lines. A line is drawn from the basion (B) to the axis spinolaminar junction $(\mathrm{C} 2 \mathrm{P})$ and is considered normal when it intersects $\mathrm{C}-2$. A second line is drawn from the opisthion $(\mathrm{O})$ to the posterior inferior corner of the body of $\mathrm{C}-2$ (C2A) and is considered normal when it intersects with the posterior arch of C-1 (Fig. 6). AOD is suggested when both lines miss their intersection.

\section{Statistical Analysis}

Mean combined CCI values between left and right joints and between sagittal and coronal measurements were compared using a 2-tailed t-test for unequal variance. ${ }^{19}$ General linear models were used to examine mean differences on continuous measurements between non-AOD and AOD patients. The partial eta squared statistic was used as a measure for effect size. Linear regression analyses with a single predictor of age were used to predict CCI measurements. These analyses are presented using scatter plots with a regression line, a Pearson correlation coefficient, and $95 \%$ confidence interval. A receiver operating characteristic (ROC) analysis was conducted to obtain a discriminator value for AOD and non-AOD patients using the variable with the largest effect size from the series of general linear models. The cut-score was set at the point that maximized the sum of sensitivity and specificity. A second ROC analysis was used to compare the area under the curve for standard diagnostic tests. SPSS version 22 and MedCalc version 13.2 were used for statistical analy-

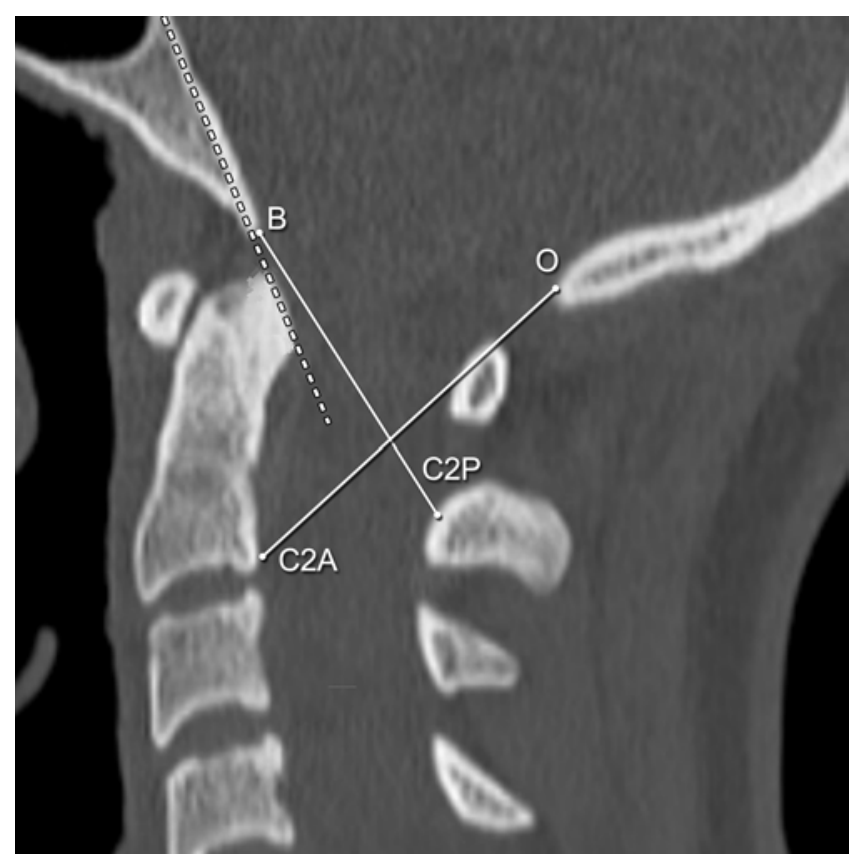

FIG. 6. Midsagittal CT scan of the upper cervical spine depicting the Wackenheim line (dotted line), suggestive of AOD when a tangential line from the clivus fails to intersect with the odontoid. Lee X-lines are also depicted with solid lines extending from the basion (B) to the axial spinolaminar junction $(\mathrm{C} 2 \mathrm{P})$ and from the opisthion $(\mathrm{O})$ to the posterior inferior corner of the body of C-2 (C2A). Lee X-lines are suggestive of $A O D$ when both lines miss their intersection.

ses and $\mathrm{p}$ values less than 0.05 were considered statistically significant.

\section{Results}

\section{Patient Demographics}

The non-AOD group included 30 men (50.8\%) and 29 women $(49.2 \%)$ with a mean age of $42.4 \pm 16$ years (range $19-87$ years). The AOD group included 10 men (45.5\%) and 12 women $(54.5 \%)$ with a mean age of $38.2 \pm 9.7$ years (range 20-56 years). There was no significant difference in average age between the two groups $(p=0.25)$.

\section{Measurements}

The results of measurements taken in the AOD and non-AOD groups including means, standard deviations, significance values, and effect sizes are presented in Table 1. Interrater reliabilities were calculated using single-class intraclass correlation coefficient and within a 95\% CI ranging from 0.38-0.76. However, interrater reliabilities from patient-to-patient analysis between both physicians within a $95 \%$ CI were all above 0.98 for CCI measurements.

\section{$\mathrm{CCl}$ Measurements in Non-AOD Patients}

The mean CCI measurement for non-AOD patients was $0.89 \pm 0.12 \mathrm{~mm}$ and was calculated using the average right and left coronal and sagittal measurements for each patient. We collected 16 measurements for each of the 59 
TABLE 1. Results for measurements performed in 81 patients

\begin{tabular}{|c|c|c|c|c|c|c|c|c|}
\hline \multirow[b]{2}{*}{ Criterion } & \multicolumn{3}{|c|}{ Non-AOD $(n=59)$} & \multicolumn{3}{|c|}{$\mathrm{AOD}(\mathrm{n}=22)$} & \multirow[b]{2}{*}{$p$ Value } & \multirow{2}{*}{$\begin{array}{l}\text { Effect } \\
\text { Size }\end{array}$} \\
\hline & Mean & $\mathrm{SD}$ & $95 \% \mathrm{Cl}$ & Mean & SD & $95 \% \mathrm{Cl}$ & & \\
\hline $\mathrm{CCl}(\mathrm{mm})$ & 0.89 & 0.12 & $0.88-0.91$ & 3.35 & 0.18 & $2.98-3.73$ & $<0.001$ & 0.58 \\
\hline Powers ratio & 0.71 & 0.08 & $0.69-0.74$ & 1.02 & 0.20 & $0.93-1.11$ & $<0.001$ & 0.55 \\
\hline Wholey BDI (mm) & 6.53 & 1.69 & $6.09-6.98$ & 11.7 & 3.75 & $10.0-13.3$ & $<0.001$ & 0.48 \\
\hline Harris BAI (mm) & 5.41 & 2.20 & $4.83-5.98$ & 9.59 & 3.76 & $7.93-11.3$ & $<0.001$ & 0.33 \\
\hline Sun ratio & 1.00 & 0.55 & $0.86-1.14$ & 1.94 & 0.85 & $1.56-2.32$ & $<0.001$ & 0.30 \\
\hline
\end{tabular}

patients and 944 measurements for the cohort (Tables 1 and 2) from considerable magnification on each slide to facilitate measurement. The single largest CCI measurement in the non-AOD patients was $1.4 \mathrm{~mm}(0.1 \%, 1$ of 944 measurements). All of the mean sagittal or coronal CCIs for either joint were less than $1.3 \mathrm{~mm}$ in all patients, and the largest mean right CCI (RCCI) or left CCI (LCCI) was $1.2 \mathrm{~mm}(0.8 \%, 1$ of 118 views of the joints). The mean condylar sum was $1.8 \pm 0.2 \mathrm{~mm}$, and the 2 largest condylar sum values were $2.2 \mathrm{~mm}$ (Patient 1) and $2.0 \mathrm{~mm}$ (Patient 11).

\section{$\mathrm{CCl}$ Analysis With Sex and Age}

The mean RCCI for the non-AOD group was larger in males $(0.92 \pm 0.08 \mathrm{~mm})$ than in females $(0.88 \pm 0.08 \mathrm{~mm}$, $\mathrm{p}=0.049$ ). However, the effect size was small (partial eta squared $=0.07$ ) and considered to be clinically insignificant. The mean LCCI was not significantly different between sexes $(p=0.37)$.

Age was significantly, although modestly, correlated with the combined left and right mean CCI $(\mathrm{r}(59)=0.26$, $\mathrm{p}=0.048)$ and left mean CCI $(\mathrm{r}(59)=0.26, \mathrm{p}=0.045)$, but not with the right mean CCI $(\mathrm{r}(59)=0.16, \mathrm{p}=0.21)$. A simple linear regression with age prediction suggested a $0.001 \mathrm{~mm}$ increase on average annually $(\beta=0.001, \mathrm{p}<$ 0.048 ). The results of our regression analysis indicated that patient age explained $6.7 \%$ of the total variance in CCI measurement $\left(\mathrm{R}^{2}=0.067, \mathrm{~F}(1,58)=4.07, \mathrm{p}<0.05\right)$ (Fig. 7).

Linear regression between CCI and age showed an annual increase of $0.001 \mathrm{~mm}$ (weak positive Pearson correlation coefficient $=+0.260, \mathrm{p}<0.05)$ and when RCCI and LCCI were plotted independently, both lines were virtually superimposed. The LCCI weakly correlated to age $($ Pearson correlation coefficient $=+0.262, \mathrm{p}<0.05$ ) compared with the RCCI (Pearson correlation coefficient $=+0.164, p<0.05$ ) (Fig. 7). Due to these weak correlations, the differences in CCI between age groups and the different correlation coefficients between the right and left CCIs were considered clinically insignificant.

\section{Symmetry}

Symmetry between the left and right $\mathrm{Oc}-\mathrm{Cl}$ joints was assessed by comparing RCCI and LCCI for each nonAOD patient. Symmetry was noted with a mean difference between left and right sides of $0.019 \mathrm{~mm}(\mathrm{p}=0.17)$. Sagittal and coronal measurements showed cohesiveness with a difference of means of $0.008 \mathrm{~mm}(\mathrm{p}=0.56)$.

\section{$\mathrm{CCl}$ Measurements in AOD Patients}

Tables 2 and 3 include the results from the combined CCIs obtained from 22 AOD patients. Of 352 measurements taken from these patients' CT scans, the mean combined CCI was $3.34 \pm 1.8 \mathrm{~mm}$ (range 1.5-6.4 mm), mean RCCI was $3.29 \pm 1.75 \mathrm{~mm}$ (range 1.4-8.3 mm), and mean LCCI was $3.39 \pm 1.85 \mathrm{~mm}$ (range $1.5-6.8 \mathrm{~mm}$ ). The shortest single CCI measurements in the AOD patients were $1.1 \mathrm{~mm}$ (5 of 352 measurements, $1.4 \%$ ) and $1.2 \mathrm{~mm}$ (5 of 352 measurements, $1.4 \%$ ) in Patient 5 and Patient 14, respectively. One mean coronal RCCI (Patient 5) was 1.0 $\mathrm{mm}(1.14 \%, 1$ of 88 left-right sagittal or coronal means); however, the ipsilateral sagittal mean was $1.8 \mathrm{~mm}$ and the LCCI for this patient was $1.6 \mathrm{~mm}$. The shortest mean RCCI or LCCI was $1.4 \mathrm{~mm}(2.27 \%, 1$ of 44 joints) also in Patient 5. The mean condylar sum for all 22 AOD patients was $6.7 \pm 2.7 \mathrm{~mm}$ and the shortest condylar sums were 3.0 $\mathrm{mm}$ (Patient 1) and $3.5 \mathrm{~mm}$ (Patient 1).

Symmetry between left and right $\mathrm{Oc}-\mathrm{C} 1$ joints in AOD patients was also assessed. The mean difference between joints was $22 \% \pm 20 \%$. Nine patients had differences greater than $20 \%$, and 3 patients had differences greater than $50 \%$.

ROC Analysis of CCl in Non-AOD and AOD Patients

ROC analysis (Fig. 8) of the means of the CCI for both

TABLE 2. Mean sagittal, coronal, and combined $\mathrm{CCl}$ for right and left $\mathrm{Oc}-\mathrm{C} 1$ junction*

\begin{tabular}{|c|c|c|c|c|c|c|}
\hline \multirow[b]{2}{*}{ Parameter } & \multicolumn{3}{|c|}{ Non-AOD $(n=59)$} & \multicolumn{3}{|c|}{$\mathrm{AOD}(\mathrm{n}=22)$} \\
\hline & Sagittal & Coronal & Combined & Sagittal & Coronal & Combined \\
\hline Right CCl & $0.89 \pm 0.12$ & $0.91 \pm 0.12$ & $0.90 \pm 0.12$ & $3.44 \pm 1.98$ & $3.35 \pm 1.91$ & $3.29 \pm 1.75$ \\
\hline Left CCl & $0.89 \pm 0.13$ & $0.88 \pm 0.12$ & $0.88 \pm 0.12$ & $3.23 \pm 1.60$ & $3.35 \pm 1.73$ & $3.39 \pm 1.85$ \\
\hline Total & $0.89 \pm 0.12$ & $0.90 \pm 0.12$ & $0.89 \pm 0.12$ & $3.34 \pm 1.79$ & $3.35 \pm 1.82$ & $3.34 \pm 1.80$ \\
\hline
\end{tabular}

* Values shown are presented as mean \pm SD in millimeters. 

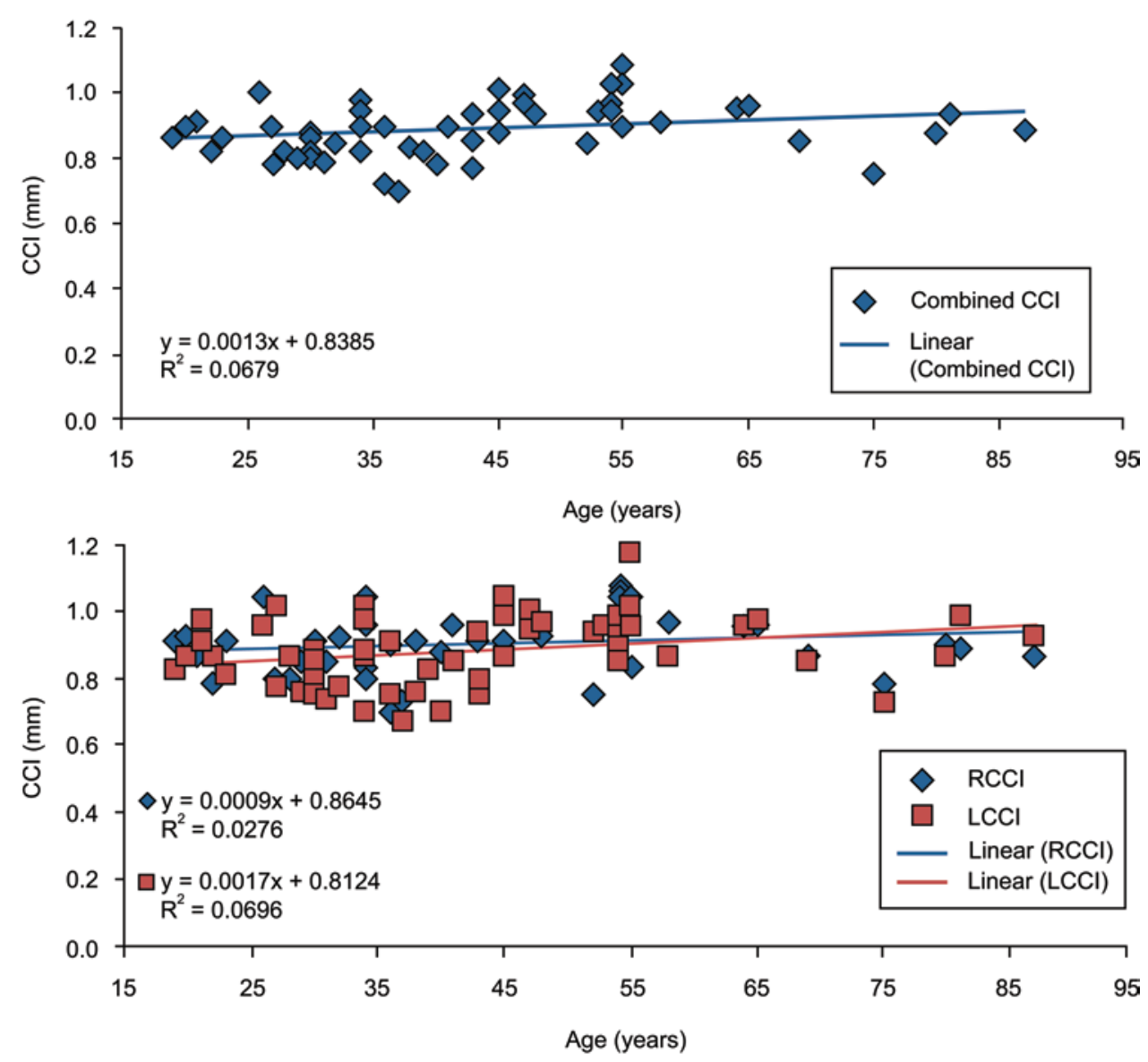

FIG. 7. Linear regression between combined (upper) and right and left (lower) $\mathrm{CCl}$ and age shows no significant difference between age groups. The annual increase in combined $\mathrm{CCl}$ (upper) was $0.001 \mathrm{~mm}$. The regression suggests a left-right cohesiveness in symmetry (lower) throughout adulthood (Pearson correlation coefficient $=$ left $+0.262, p<0.05$; right $=+0.164, p<0.05$ ). Figure is available in color online only.

sides yielded a cutoff value of $1.3 \mathrm{~mm}$ to achieve $100 \%$ sensitivity and specificity.

This cutoff value was rounded to $1.5 \mathrm{~mm}$ to facilitate use, thus increasing to 5 the number of standard deviations from the mean (mean CCI $+\left[5^{*} \mathrm{SD}\right]=0.893 \mathrm{~mm}+$ $\left[5^{*} 0.12 \mathrm{~mm}\right]=1.49 \mathrm{~mm}$ ) while maintaining the same diagnostic strength $(100 \%$ sensitivity and $0 \%$ false-negative rate). Most patients (21 of 22, 95.5\%) had bilateral AOD, and combined CCIs for both joints was greater than 1.5 $\mathrm{mm}$ in all patients.

\section{Standard Diagnostic Tests}

Table 1 includes the mean results from 4 standard diagnostic tests in all 81 patients, and Table 3 includes the measurements performed in 22 AOD patients. Among the AOD population, the diagnosis was suggested by all 4 standard tests in only 2 patients. Two patients had the diagnosis supported by 3 tests, and 6 patients had the diagnosis supported by 2 tests. Three patients had 1 positive test result, and 9 patients (41\%) had 4 negative test results. The Wackenheim clivus line and Lee X-lines were each abnormal in 9 patients; however, they were both abnormal in only 4 patients.

\section{Sensitivity and Specificity Analysis for AOD Patients}

Table 4 presents results from the sensitivity and specificity analyses for AOD patients. For patients with AOD, the Powers ratio was positive for AOD in 12 of 22 patients (54.5\%), Wholey BDI was positive in 10 of 22 patients (45.5\%), Harris BAI was positive in 6 of 22 patients (27.3\%), Sun ratio was positive in 5 of 22 patients (22.7\%), and the Wackenheim clivus line and Lee X-lines were each abnormal in 9 of 22 patients (40.9\%).

Table 5 presents the sensitivity and false-negative rates for diagnosing AOD using the CCI and condylar sum. To calculate the sensitivity and specificity of the CCI in patients with AOD, each patient was considered as a truepositive for AOD if the mean CCI for either side was greater than or equal to 1 of 3 different discriminators: 1.5, 2, or $2.5 \mathrm{~mm}$. A CCI of $\geq 1.5 \mathrm{~mm}$ had the highest sensitivity (100\%) for AOD with a false-negative rate of $0 \%$. Additionally, sensitivity was calculated for all AOD patients considered as true-positives if the condylar sum for each patient was $\geq 3 \mathrm{~mm}$ or $\geq 5 \mathrm{~mm}$. A condylar sum value $\geq 3$ $\mathrm{mm}$ was $100 \%$ sensitive with a false-negative rate of $0 \%$.

\section{Sensitivity and Specificity Analysis for Non-AOD Patients}

Table 4 includes the results from all the standard diag- 
TABLE 3. Results of standard tests and CCI measurements in 22 AOD patients

\begin{tabular}{|c|c|c|c|c|c|c|c|c|c|c|c|c|c|}
\hline \multirow[b]{2}{*}{$\begin{array}{l}\text { Patient } \\
\text { No. }\end{array}$} & \multirow[b]{2}{*}{$\begin{array}{l}\text { Age } \\
\text { (yrs), } \\
\text { Sex }\end{array}$} & \multirow{2}{*}{$\begin{array}{l}\text { Tectorial } \\
\text { Membrane } \\
\text { Rupture } \\
\text { (MRI) }\end{array}$} & \multirow[b]{2}{*}{$\begin{array}{l}\text { Other MRI/CT } \\
\text { Abnormality }\end{array}$} & \multicolumn{6}{|c|}{ Standard Diagnostic Test Results } & \multicolumn{4}{|c|}{ Right \& Left CCI (mm) } \\
\hline & & & & $\begin{array}{c}\text { Powers } \\
\text { Ratio }\end{array}$ & $\begin{array}{l}\text { Wholey } \\
\text { BDI (mm) }\end{array}$ & $\begin{array}{l}\text { Harris } \\
\text { BAl } \\
(\mathrm{mm})\end{array}$ & $\begin{array}{l}\text { Sun } \\
\text { ratio }\end{array}$ & $\begin{array}{l}\text { Wackenheim } \\
\text { Line }\end{array}$ & $\begin{array}{c}\text { Lee } \\
\text { X-Lines }\end{array}$ & $\mathrm{RCCl}$ & $\mathrm{LCCl}$ & Asymmetry & $\begin{array}{l}\text { Condylar } \\
\text { Sum }\end{array}$ \\
\hline 1 & $20, F$ & + & $\begin{array}{l}\text { AAD, Type } 2 \\
\text { odontoid Fx }\end{array}$ & 0.9 & 9.5 & 9.7 & 1.0 & & & 3.0 & 2.5 & & 5.5 \\
\hline 2 & $24, \mathrm{M}$ & + & $\begin{array}{c}\text { Pseudomenin- } \\
\text { gocele, AAD, } \\
\text { TAL rupture }\end{array}$ & 1.0 & 12.0 & 8.7 & 2.4 & + & & 1.7 & 3.0 & + & 4.7 \\
\hline 3 & $28, \mathrm{M}$ & + & AAD & 0.9 & 12.0 & 6.0 & 1.8 & & & 3.0 & 2.6 & & 5.6 \\
\hline 4 & $31, F$ & + & AAD & 0.9 & 11.4 & 9.0 & 1.7 & & + & 4.0 & 2.4 & + & 6.4 \\
\hline 5 & $32, \mathrm{M}$ & + & $\begin{array}{l}\text { SAH, AAD, } \\
\text { TAL rupture, } \\
\text { \& C1-2 } \\
\text { edema/blood }\end{array}$ & 1.0 & 7.1 & 9.5 & 1.7 & & & 1.4 & 1.6 & & 3 \\
\hline 6 & $33, F$ & + & & 0.8 & 6.7 & 6.1 & 1.0 & & & 2.0 & 1.5 & + & 3.5 \\
\hline 7 & $34, F$ & + & AAD & 1.4 & 10.5 & 9.8 & 2.0 & + & & 2.4 & 2.4 & & 4.8 \\
\hline 8 & $34, F$ & + & AAD & 1.2 & 6.6 & 10.4 & 4.2 & + & + & 4.2 & 4.7 & & 8.9 \\
\hline 9 & $34, \mathrm{~F}$ & + & & 1.0 & 17.4 & 7.3 & 3.3 & & + & 1.9 & 1.7 & & 3.6 \\
\hline 10 & $35, \mathrm{M}$ & + & $\begin{array}{l}\text { Type } 1 \text { odontoid } \\
\text { Fx, AAD }\end{array}$ & 1.3 & 13.6 & 12.5 & 2.9 & + & + & 4.1 & 4.3 & & 8.4 \\
\hline 11 & $37, \mathrm{M}$ & + & & 0.9 & 13.1 & 5.4 & 2.9 & & & 3.6 & 4.2 & & 7.8 \\
\hline 12 & $37, \mathrm{M}$ & + & SAH \& AAD & 0.9 & 11.0 & 11.0 & 1.5 & & & 2.1 & 2.9 & + & 5 \\
\hline 13 & $38, F$ & + & & 1.1 & 17.4 & 11.8 & 2.0 & + & & 6.0 & 6.8 & & 12.8 \\
\hline 14 & $40, F$ & + & & 1.0 & 14.0 & 12.0 & 1.7 & & & 2.8 & 2.8 & & 5.6 \\
\hline 15 & $40, F$ & + & C-1 burst Fx & 1.1 & 18.6 & 13.1 & 2.2 & + & + & 8.3 & 3.6 & + & 11.9 \\
\hline 16 & $40, \mathrm{~F}$ & + & & 1.1 & 14.2 & 12.7 & 1.9 & & & 5.0 & 6.0 & & 11 \\
\hline 17 & $42, \mathrm{~F}$ & + & & 0.8 & 8.8 & 4.3 & 1.3 & & + & 3.1 & 2.4 & + & 5.5 \\
\hline 18 & $43, M$ & + & $\begin{array}{l}\text { C-1, C-2, \& C-7 } \\
\text { Fx }\end{array}$ & 0.9 & 10.2 & 9.5 & 1.5 & + & & 2.8 & 2.8 & & 5.6 \\
\hline 19 & $53, F$ & + & & 1.6 & 17.4 & 20.6 & 1.8 & + & + & 7.3 & 2.9 & + & 10.2 \\
\hline 20 & $55, \mathrm{M}$ & + & AAD & 0.8 & 5.7 & 4.0 & 0.7 & & + & 2.4 & 3.5 & + & 5.9 \\
\hline 21 & $55, \mathrm{M}$ & + & & 0.9 & 9.4 & 5.5 & 2.5 & & + & 1.9 & 1.8 & & 3.7 \\
\hline 22 & $56, F$ & + & & 1.0 & 10.1 & 12.1 & 0.6 & + & & 1.8 & 6.0 & + & 7.8 \\
\hline
\end{tabular}

$\mathrm{AAD}=$ atlantoaxial dislocation; $\mathrm{Fx}=$ fracture $\mathrm{SAH}=$ subarachnoid hemorrhage $; \mathrm{TAL}=$ transverse atlantal ligament; + = present.

nostic tests performed in the 59 non-AOD patients. The mean Powers ratio was $0.7 \pm 0.08$ (range $0.5-0.9$ ), mean Wholey BDI was $6.5 \pm 1.7 \mathrm{~mm}$ (range $3-10.2 \mathrm{~mm}$ ), mean Harris BAI was $5.4 \pm 2.2 \mathrm{~mm}$ (range $0.7-11.7 \mathrm{~mm}$ ), and mean Sun ratio was $1.0 \pm 0.55$ (range 0.3-3.2). For different CCI discriminators $(\geq 1.5,2$, or $2.5 \mathrm{~mm})$, there were no false-positives for the Powers ratio, Wholey BDI, and Harris BAI. Only 1 patient was false-positive for AOD using the Sun ratio $(3.2 \mathrm{~mm}$, false-positive rate $=1.7 \%$ ). The Wackenheim clivus line was falsely positive for AOD in 27 of 59 patients $(45.8 \%)$ and the Lee X-lines test was falsely positive in 4 of 59 patients (6.8\%).

\section{Discussion}

After reviewing with great interest the articles published in 2007 by Pang et al., ${ }^{18,19}$ in which the authors endeavored to study the $\mathrm{CCI}$ in the pediatric population, we decided to perform a similar study in the adult population to establish the normal CCI parameters in non-AOD patients, compare them with AOD patients, and assess the relevance of the standard diagnostic tests in the modern radiological era.

In a study from 2013, Gire et al. ${ }^{7}$ proposed 3 premises: 1) Normative data from the study by Pang et al..$^{18,19}$ did not demonstrate a statistical change of CCI from birth to 18 years; therefore, the use of the CCI may also be applicable to adult populations. 2) The number of measurements taken should be reduced from 8 per joint to 1 to make the technique more practical. 3) A cutoff was set for AOD of $2.5 \mathrm{~mm}$ for the revised CCI and $5.0 \mathrm{~mm}$ for the condylar sum. After performing the present study, we found these 3 premises to be inconsistent with our results.

As normative data from an adult population to assess the normal CCI in non-AOD patients are lacking in the literature, we studied a sufficiently large number of con- 


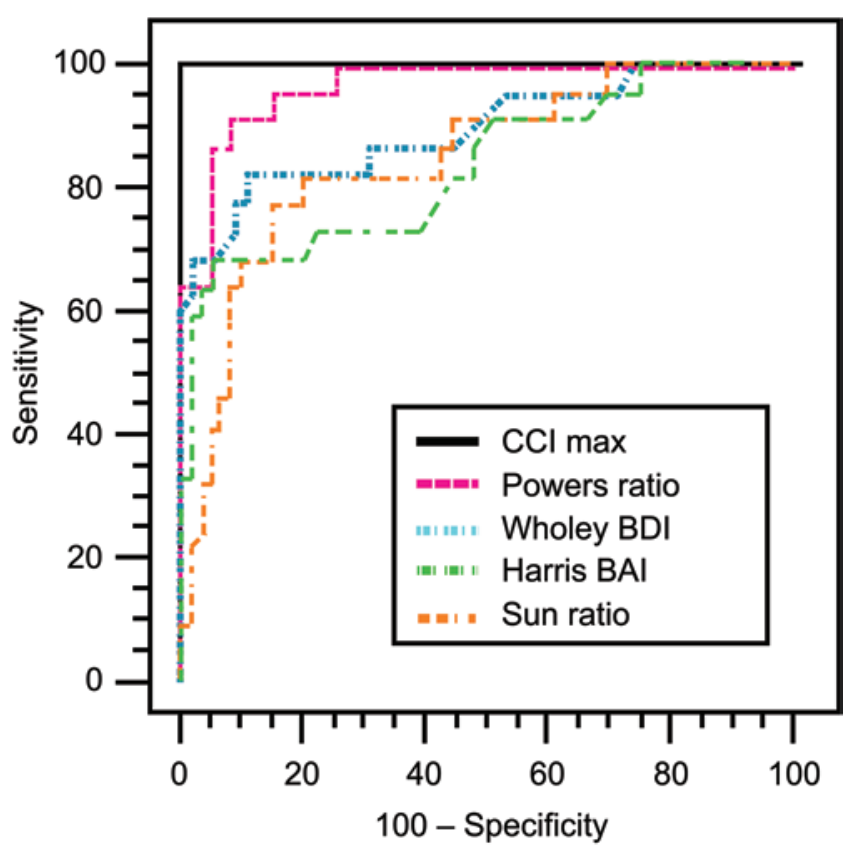

FIG. 8. ROC curves for $\mathrm{CCl}$, Powers ratio, Wholey $\mathrm{BDI}$, Harris $\mathrm{BAI}$, and Sun ratio. ROC analysis for $\mathrm{CCl}$ yielded a cutoff of $1.3 \mathrm{~mm}(100 \%$ sensitivity and specificity) with an area under the curve of 1.0 (95\% Cl 0.961.0). Pairwise comparison of ROC curves (CCl vs standard tests) showed that $\mathrm{CCl}$ is significantly more accurate than the other standard tests for diagnosing AOD ( $p \leq 0.05)$. Figure is available in color online only.

secutive patients admitted to the emergency department at our institution with mild or non-upper cervical trauma who had a CT scan including the CVJ as part of their diagnostic workup.

\section{Normal $\mathrm{CCl}$}

We assessed each joint individually in 59 non-AOD adults and found the mean CCI to be $0.387 \mathrm{~mm}$ shorter than the mean CCI reported in the pediatric population ${ }^{19}$ (0.893 $\mathrm{mm}$ vs $1.28 \mathrm{~mm})$, ranging mostly from 0.7 to 1.0 $\mathrm{mm}$, with only 1 patient having a mean of $1.2 \mathrm{~mm}$. Great cohesiveness was evident among all patients in terms of age, sex, and use of sagittal or coronal cuts and, as shown in Fig. 7 (lower), the two lines are superimposed with what is practically an insignificant annual increase with age (0.001 $\mathrm{mm} /$ year). The condylar sum, obtained from the mean of each patient's RCCI and LCCI, was also shorter by $1.41 \mathrm{~mm}$ than the results obtained by Gire et al. ${ }^{7}$ (1.8 $\mathrm{mm}$ vs $3.21 \mathrm{~mm})$. Contrary to the results of Pang et al., ${ }^{18,19}$ our results showed that symmetry was not universally observed among non-AOD patients, and 7 of 59 patients had a difference greater than $20 \%$ between left and right sides. However, none of these patients had a right or left mean CCI greater than $1.0 \mathrm{~mm}$, and all were neurologically and clinically intact.

\section{Adequate $\mathrm{CCl}$ Measurement}

The individual CCI means per side (right and left) of each sagittal and coronal CT scan in all non-AOD patients were similar and showed no statistically significant differences ( $p>0.05)$. However, each individual measurement could show a variability of as much as $0.5 \mathrm{~mm}$ between a sagittal and a coronal ipsilateral slice, and in some cases even on opposite sides of the joint on a single slice. We consider this difference to be too large to be disregarded. For this reason, we agree with Pang et al. ${ }^{19}$ on the necessity of obtaining 4 equidistant measurements on each sagittal and coronal slice from each joint, as the complex 3D "ballsocket" configuration of the joint may provide different CCI lengths throughout its surface.

Measuring 8 different points per joint (16 per patient) might be less practical than measuring a single one. Nonetheless, the severity of AOD and the great necessity to adequately and accurately diagnose it are strong enough reasons to support their use, taking the interpreting physician only an additional 1-2 minutes. If the $\mathrm{Oc}-\mathrm{C} 1$ joint is widely and obviously separated, 1 or 2 measurements per joint may suffice. Moreover, the CCI might not be necessary in patients with clearly visible AOD. ${ }^{18,19}$ All 8 measurements per joint should be taken when in doubt. Sufficient magnification of the image is required, such that the joint fills most of a regular PC monitor, and the built-in tools in the image processor should be used to measure the space between the cortices of the occipital condyle and the superior endplate of C-1. We use the Web Dominator (DR Systems, Inc.) (Fig. 9). Crevices and uneven spaces should be avoided, and results are processed through basic means to obtain an RCCI and LCCI.

\section{MRI/CT Abnormal Findings in Patients With AOD}

All 22 patients with AOD had CVJ disruption evidenced by tectorial membrane rupture (high-intensity changes on

TABLE 4. Sensitivity, specificity, false-negative rates, and false-positive rates for AOD using standard diagnostic tests in 59 non-AOD and 22 AOD patients

\begin{tabular}{lcccc}
\hline \multicolumn{1}{c}{ Measurement } & Sensitivity (\%) & Specificity (\%) & False-Negative Rate (\%) & False-Positive Rate (\%) \\
\hline Powers ratio & 54.5 & 100 & 45.5 & 0 \\
\hline Wholey BDI & 45.5 & 100 & 54.5 & 0 \\
\hline Harris BAI & 27.3 & 100 & 72.7 & 0 \\
\hline Sun ratio & 22.7 & 98.3 & 77.3 & 1.7 \\
\hline Wackenheim line & 40.9 & 54.2 & 59.1 & 45.8 \\
\hline Lee X-lines & 40.9 & 93.2 & 59.1 & 6.8 \\
\hline
\end{tabular}


TABLE 5. Sensitivity and false-negative rates for AOD using the $\mathrm{CCl}$ and condylar sum in $22 \mathrm{AOD}$ patients

\begin{tabular}{lcc}
\hline \multicolumn{1}{c}{ Measurement } & Sensitivity (\%) & False-Negative Rate (\%) \\
\hline $\mathrm{CCl} \geq 1.5 \mathrm{~mm}$ & 100 & 0 \\
\hline $\mathrm{CCl} \geq 2 \mathrm{~mm}$ & 90.1 & 13.6 \\
\hline $\mathrm{CCl} \geq 2.5 \mathrm{~mm}$ & 81.8 & 22.7 \\
\hline Condylar sum $\geq 3 \mathrm{~mm}$ & 100 & 0 \\
\hline Condylar sum $\geq 5 \mathrm{~mm}$ & 68.2 & 18.2 \\
\hline
\end{tabular}

T2-weighted or STIR MRI and loss of continuity of the line extending from the dens to the upper portion of the clivus), and atlantooccipital membrane rupture and blood or edema surrounding $\mathrm{Oc}-\mathrm{C} 1$ and $\mathrm{C} 1-2$ on $\mathrm{T} 2$-weighted midsagittal MRI. Additionally, 10 (45.4\%) AOD patients had evidence of atlantoaxial dislocation, $2(9.1 \%)$ patients had Type 1 and Type 2 odontoid fractures, 2 (9.1\%) patients had transverse ligament rupture, and 1 had evidence of blood/edema on C1-2. Other lesions not inherent and distant to the CVJ were also noted in some patients, but were not deemed significant for analysis.

\section{The $\mathrm{CCl}$ in AOD}

Since the description of the CCI in children, multiple authors have determined, without sufficient statistical evidence, that the normal upper value for the distance between the occipital condyle and C-1 in adults is between $2.0 \mathrm{~mm}$ and $2.5 \mathrm{~mm}$. $^{5,726,28}$ Biostatistical and ROC curve analyses for these 2 proposed cutoffs together with our proposed discriminator shows that $1.5 \mathrm{~mm}$ is the more accurate cutoff, with $100 \%$ sensitivity and specificity with no false-negatives; while $2.0 \mathrm{~mm}$ and $2.5 \mathrm{~mm}$ had higher false-negative rates of $13.6 \%$ and $22.7 \%$, respectively. Better results were also evident when comparing the condylar sum values of $3.0 \mathrm{~mm}$ against $5.0 \mathrm{~mm}$. Even though our statistical analysis supports the use of a CCI $\geq 1.5 \mathrm{~mm}$ for the radiological diagnosis of AOD, we are aware that some concerns may arise regarding the small difference $(0.6 \mathrm{~mm})$ between the normal and pathological CCI. We suggest that this value $(\geq 1.5 \mathrm{~mm})$ be used as a highly suggestive indicator that a patient has AOD, especially in a clinical scenario where a patient has concomitant cervicomedullary deficits, cranial nerve palsy, cruciate paralysis, perimedullary or $\mathrm{Cl}-2$ imaging abnormalities, and tectorial membrane or atlantooccipital ligament injury.

As opposed to the CVJ in children, adults have a more rigid, less cartilaginous joint, with decreased ligamentous hydration and even calcification as patients grow older. Minimal widening between the occiput and C-1 might be enough to render the joint unstable and may not be evident on plain radiographs, which increases the probability of misdiagnosis on plain radiography. One patient in the AOD group (Patient 5) had a CCI of only $1.6 \mathrm{~mm}$, and the confirmation of instability was made during surgery. This is evidence that larger series are necessary to show the whole spectrum of the disease, especially as more patients survive the initial insult. We believe this supports our decision to tighten the index of suspicion for this disease. If the CCI is established to be $\geq 1.5 \mathrm{~mm}$ in a patient, we
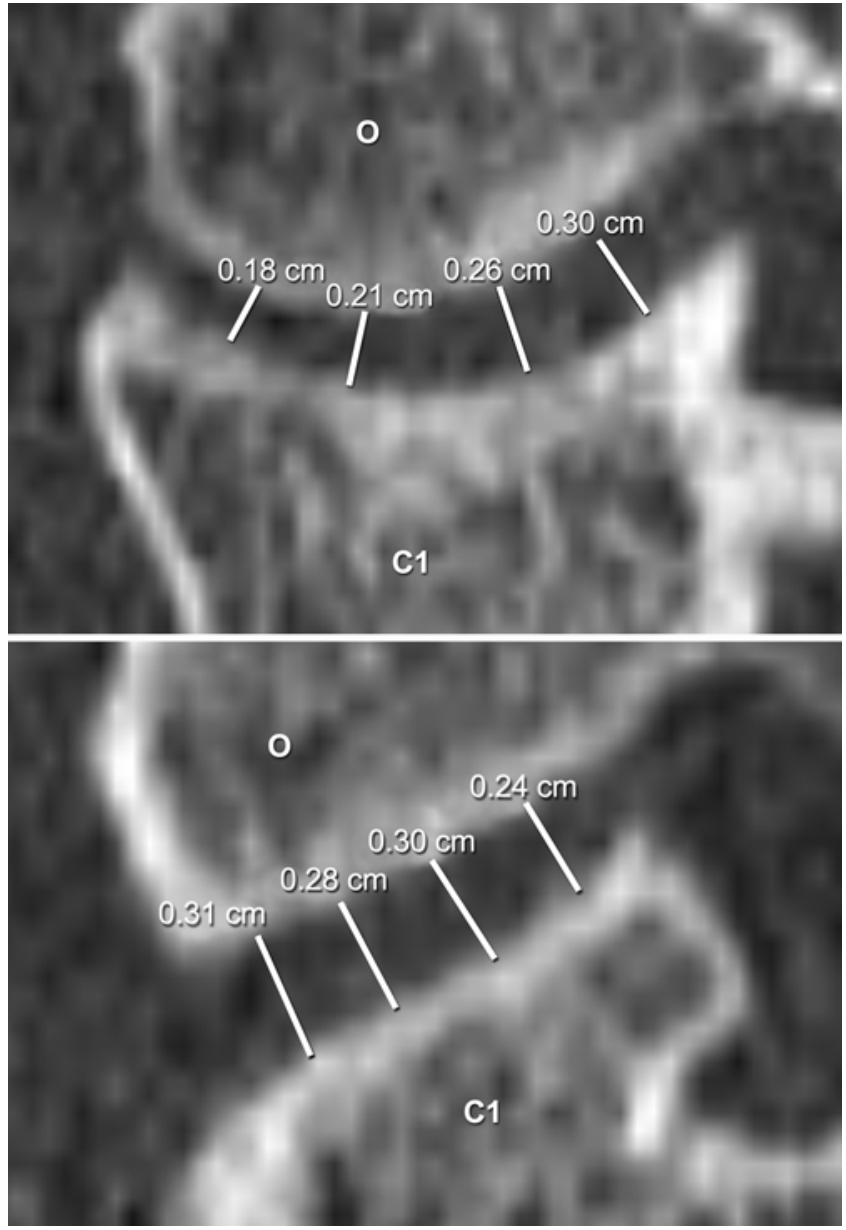

FIG. 9. Parasagittal (upper) and coronal (lower) CT scans of the right $\mathrm{Oc}-\mathrm{C} 1$ joint, with 4 equidistant $\mathrm{CCI}$ measurements per slice, with a mean $\mathrm{RCCl}$ of $2.6 \mathrm{~mm}$. Measurements were made with Web Dominator and converted from centimeters to millimeters.

believe that cervical distraction is contraindicated and the emergency room physician should immediately consult the neurosurgical department for further studies, following the current protocols for management of AOD. ${ }^{28}$

Neurological presentation, type and severity of the traumatic insult, serial MRI and CT scanning, and the neurosurgeon's and institution's own experience all have paramount importance in the diagnostic armamentarium for $\mathrm{AOD}$, and must be complementary to the CCI.

\section{Standard Diagnostic Tests}

The Powers ratio, Harris line, Wholey line, Sun ratio, Wackenheim line, and Lee X lines have all played important roles in the past for the diagnosis of AOD. However, they were initially applied in lateral plain radiographs, and they may not be relevant when CT is used. They are also limited in their ability to measure the relationships between mobile landmarks at the CVJ, which may shift or alter depending on the patient's position, and their use may result in higher false-negative ratios. ${ }^{18}$ As previously discussed in the Results section, both sensitivity and specificity for these tools are suboptimal, requiring a readjustment 
for their continued use on CT scans. The current study is arguably one of the largest to present normative data using these tools with such a modality and then comparing patients with AOD to the derived norms. They might be useful for the complementary diagnosis of this traumatic injury.

\section{Limitations}

This is a study from a tertiary neurosurgical center with all the inherent limitations of a retrospective review. Although it might represent the largest case series to date to study the CCI for the diagnosis of AOD, a prospective study would be ideal. However, the low incidence and survival rates of this pathology make this difficult to achieve.

Universal accessibility to CT scanning may be limited to higher-level trauma centers, especially in rural areas and some developing countries. In such cases, standard tests and clinical presentation will determine the management and probable transfer of the patient to specialized neurosurgical centers.

Images were assessed by physicians from our division of neurological surgery. A neuroradiologist might have offered additional significant input to the study. However, as this pathology is mainly diagnosed in the emergency department, we did not deem it necessary for the validity and reliability of this study.

\section{Conclusions}

Our analysis of the normal parameters of the CCI in the adult population helped us establish that the distance between the occipital condyle and C-1 in adults is shorter than we previously believed. This finding led us to review the CT scans of the CVJ in a larger number of AOD patients, and enabled us to propose a tighter cutoff for the CCI $(\geq 1.5 \mathrm{~mm})$ and condylar sum $(\geq 3.0 \mathrm{~mm})$, both of which are more sensitive and reliable than the present radiographic criteria. This adjustment may lower the probability of AOD passing undiagnosed.

\section{Acknowledgments}

We acknowledge Kristina Chapple, $\mathrm{PhD}$, for her invaluable help with the statistical analysis and interpretation of our results.

\section{References}

1. Astur N, Klimo P Jr, Sawyer JR, Kelly DM, Muhlbauer MS, Warner WC Jr: Traumatic atlanto-occipital dislocation in children: evaluation, treatment, and outcomes. J Bone Joint Surg Am 95:e194, 2013

2. Baron EM, Loftus CM, Vaccaro AR, Dominique DA: Anterior approach to the subaxial cervical spine in children: a brief review. Neurosurg Focus 20(2):E4, 2006

3. Bono CM, Vaccaro AR, Fehlings M, Fisher C, Dvorak M, Ludwig S, et al: Measurement techniques for upper cervical spine injuries: consensus statement of the Spine Trauma Study Group. Spine (Phila Pa 1976) 32:593-600, 2007

4. Dickman CA, Sonntag VK: Injuries involving the transverse atlantal ligament: classification and treatment guidelines based upon experience with 39 injuries. Neurosurgery 40:886-887, 1997

5. Dziurzynski K, Anderson PA, Bean DB, Choi J, Leverson GE, Marin RL, et al: A blinded assessment of radiographic criteria for atlanto-occipital dislocation. Spine 30:1427-1432, 2005

6. Ehlinger M, Charles YP, Adam P, Bierry G, Dosch JC, Steib JP, et al: Survivor of a traumatic atlanto-occipital dislocation. Orthop Traumatol Surg Res 97:335-340, 2011

7. Gire JD, Roberto RF, Bobinski M, Klineberg EO, DurbinJohnson B: The utility and accuracy of computed tomography in the diagnosis of occipitocervical dissociation. Spine $\mathbf{J}$ 13:510-519, 2013

8. Gluf WM, Brockmeyer DL: Atlantoaxial transarticular screw fixation: a review of surgical indications, fusion rate, complications, and lessons learned in 67 pediatric patients. J Neurosurg Spine 2:164-169, 2005

9. Hankinson TC, Avellino AM, Harter D, Jea A, Lew S, Pincus $\mathrm{D}$, et al: Equivalence of fusion rates after rigid internal fixation of the occiput to $\mathrm{C}-2$ with or without $\mathrm{C}-1$ instrumentation. J Neurosurg Pediatr 5:380-384, 2010

10. Harris JH Jr, Carson GC, Wagner LK: Radiologic diagnosis of traumatic occipitovertebral dissociation: 1 . Normal occipitovertebral relationships on lateral radiographs of supine subjects. AJR Am J Roentgenol 162:881-886, 1994

11. Horn EM, Feiz-Erfan I, Lekovic GP, Dickman CA, Sonntag VK, Theodore N: Survivors of occipitoatlantal dislocation injuries: imaging and clinical correlates. J Neurosurg Spine 6:113-120, 2007

12. Hwang SW, Gressot LV, Chern JJ, Relyea K, Jea A: Complications of occipital screw placement for occipitocervical fusion in children. J Neurosurg Pediatr 9:586-593, 2012

13. Hwang SW, Gressot LV, Rangel-Castilla L, Whitehead WE, Curry DJ, Bollo RJ, et al: Outcomes of instrumented fusion in the pediatric cervical spine. J Neurosurg Spine 17:397409, 2012

14. Klimo P Jr, Astur N, Gabrick K, Warner WC Jr, Muhlbauer MS: Occipitocervical fusion using a contoured rod and wire construct in children: a reappraisal of a vintage technique. J Neurosurg Pediatr 11:160-169, 2013

15. Lee C, Woodring JH, Goldstein SJ, Daniel TL, Young AB, Tibbs PA: Evaluation of traumatic atlantooccipital dislocations. AJNR Am J Neuroradiol 8:19-26, 1987

16. Oppenlander ME, Clark JC, Sonntag VK, Theodore N: Pediatric craniovertebral junction trauma. Adv Tech Stand Neurosurg 40:333-353, 2014

17. Oppenlander ME, Kalyvas J, Sonntag VK, Theodore N: Technical advances in pediatric craniovertebral junction surgery. Adv Tech Stand Neurosurg 40:201-213, 2014

18. Pang D, Nemzek WR, Zovickian J: Atlanto-occipital dislocation-part 2: The clinical use of (occipital) condyle- $\mathrm{C}_{1}$ interval, comparison with other diagnostic methods, and the manifestation, management, and outcome of atlanto-occipital dislocation in children. Neurosurgery 61:995-1015, 2007

19. Pang D, Nemzek WR, Zovickian J: Atlanto-occipital dislocation: part 1 -normal occipital condyle- $C_{1}$ interval in 89 children. Neurosurgery 61:514-521, 2007

20. Papadopoulos SM, Dickman CA, Sonntag VK, Rekate HL, Spetzler RF: Traumatic atlantooccipital dislocation with survival. Neurosurgery 28:574-579, 1991

21. Parisini P, Di Silvestre M, Greggi T, Bianchi G: C1-C2 posterior fusion in growing patients: long-term follow-up. Spine (Phila Pa 1976) 28:566-572, 2003

22. Patel JC, Tepas JJ III, Mollitt DL, Pieper P: Pediatric cervical spine injuries: defining the disease. J Pediatr Surg 36:373376,2001

23. Powers B, Miller MD, Kramer RS, Martinez S, Gehweiler JA Jr: Traumatic anterior atlanto-occipital dislocation. Neurosurgery 4:12-17, 1979

24. Rekate HL, Theodore N, Sonntag VK, Dickman CA: Pediatric spine and spinal cord trauma. State of the art for the third millennium. Childs Nerv Syst 15:743-750, 1999 
25. Schultz KD Jr, Petronio J, Haid RW, Rodts GE, Erwood SC, Alexander J, et al: Pediatric occipitocervical arthrodesis. A review of current options and early evaluation of rigid internal fixation techniques. Pediatr Neurosurg 33:169-181, 2000

26. Smorgick Y, Fischgrund JS: Occipitocervical injuries. Semin Spine Surg 25:14-22, 2013

27. Sun PP, Poffenbarger GJ, Durham S, Zimmerman RA: Spectrum of occipitoatlantoaxial injury in young children. J Neurosurg 93 (1 Suppl):28-39, 2000

28. Theodore N, Aarabi B, Dhall SS, Gelb DE, Hurlbert RJ, Rozzelle CJ, et al: The diagnosis and management of traumatic atlanto-occipital dislocation injuries. Neurosurgery 72 (Suppl 2):114-126, 2013

29. Wackenheim A: Roentgen Diagnosis of the Craniovertebral Region. New York: Springer Verlag, 1974

30. Walters BC, Hadley MN, Hurlbert RJ, Aarabi B, Dhall SS, Gelb DE, et al: Guidelines for the management of acute cervical spine and spinal cord injuries: 2013 update. Neurosurgery 60 (Suppl 1):82-91, 2013

31. Wholey MH, Bruwer AJ, Baker HL Jr: The lateral roentgenogram of the neck; with comments on the atlanto-odontoidbasion relationship. Radiology 71:350-356, 1958

32. Yerramneni VK, Chandra PS, Kale SS, Lythalling RK, Mahapatra AK: A 6-year experience of 100 cases of pediatric bony craniovertebral junction abnormalities: treatment and outcomes. Pediatr Neurosurg 47:45-50, 2011

\section{Disclosures}

The authors report no conflict of interest concerning the materials or methods used in this study or the findings specified in this paper.

\section{Author Contributions}

Conception and design: Theodore, Martinez-del-Campo, Kalb. Acquisition of data: Martinez-del-Campo, Kalb, Soriano-Baron. Analysis and interpretation of data: Martinez-del-Campo. Drafting the article: Martinez-del-Campo. Critically revising the article: Theodore, Kalb, Soriano-Baron, Turner, Neal. Reviewed submitted version of manuscript: Theodore, Uschold. Statistical analysis: Martinez-del-Campo. Study supervision: Theodore.

\section{Correspondence}

Nicholas Theodore, c/o Neuroscience Publications, Barrow Neurological Institute, St. Joseph's Hospital and Medical Center, 350 W. Thomas Rd., Phoenix, AZ 85013.email: neuropub@ dignityhealth.org. 